\title{
Entry of SARS-CoV2 through the basal surface of alveolar endothelial cells - A proposed mechanism mediated by CD147 in Covid-19
}

\author{
Francia Carolina Acosta Saltos ${ }^{1}$ and Alejandro David Acosta Saltos ${ }^{1,2}$ \\ 1. Lansdell Research House, London, United Kingdom \\ 2. Chelsea and Westminster Hospital, London, United Kingdom
}

Correspondence to: Dr Alejandro David Acosta Saltos, MBBS PhD, Emergency Medicine Department, Chelsea and Westminster Hospital, London, United Kingdom, Email: AlejandroDavid.AcostaSaltos@chelwest.nhs.uk

\section{Abstract}

Severe Covid-19 disease is associated with endothelial infection, viraemia, and multi-organ dysfunction. The process through which SARS-CoV2 causes severe disease is yet to be determined. Here, we propose that in severe Covid-19 infection, SARS-CoV2 reaches the host bloodstream by infecting endothelial cells through their basal surface. This occurs, independently of ACE2, through CD147, a putative SARS-CoV2 receptor. The pathway proposed here encourages research on the mechanisms mediating endothelial cell infection in Covid-19.

\section{Background}

Severe Covid-19 disease represents a global health crisis (OECD, 2020). Although most Covid-19 cases are self-limiting respiratory infections, severe disease is often characterised by multiple organ dysfunction and death (Huang et al., 2020; Zhou et al., 2020). There is growing evidence that endothelial dysfunction is a key feature of Covid-19 (Sardu et al., 2020, p. 19) and that metabolic syndrome diseases put those affected at a higher risk of severe disease (He et al., 2020; Yang et al., 2020; Zhou et al., 2020). Recently, endothelial infection and SARS-CoV viraemia have been described as key pathological features of severe Covid19 (Chen et al., 2020; Varga et al., 2020). However, the mechanism through which endothelial cells are infected by SARS-CoV2 has not yet been determined.

The anatomical arrangement of alveolar epithelial and endothelial cells, the subcellular pattern of ACE2 expression in these cells, and the discovery of a novel SARS-CoV2 receptor suggest a mechanism for endothelial infection in severe Covid-19.

\section{Epithelial cells release human coronaviruses from their basal surface}

In the alveoli, epithelial and endothelial cells demonstrate a polarised arrangement. They have their basal cell surfaces attached to a basement membrane, while their apical surfaces interact 
with either the alveolar cavity or bloodstream, respectively (Morgenroth and Ebsen, 2008). In vitro studies have demonstrated that human coronavirus infections of polarised epithelial cells result in preferential release of progeny viral particles from the apical surface of these cells (Cong and Ren, 2014; Jia et al., 2005; Pyrc et al., 2010; Sims et al., 2008; Tao et al., 2013; Tseng et al., 2005; Wang et al., 2000). However, a small proportion of all viral release occurs from the basal surface of SARS- or MERS-CoV infected polarised epithelial cells (Tao et al., 2013) (Figure 1: A \& B).

The proximity of epithelial and endothelial cells in the alveoli suggests that SARS-CoV2 may infect both types of cells in succession, ultimately resulting in release of virus to the blood. At times, only $100 \mathrm{~nm}$ of basement membrane separates the basal surfaces of epithelial and endothelial cells in the alveoli (Morgenroth and Ebsen, 2008). In vitro studies demonstrate that SARS-CoV and MERS-CoV, are released from the basal surface of infected polarised epithelial cells (Tao et al., 2013). In vivo, this could mean that infected alveolar epithelial cells release viral particles to the basement membrane they share with endothelial cells. If this is the case then, alveolar endothelial cells might become exposed to viral particles at their basal surface, and thus become infected. Since endothelial cells are in direct contact with the bloodstream, SARS-CoV2 viraemia may occur as a result of viral release by the infected alveolar endothelium.

\section{SARS-CoV2 can infect endothelial cells via ACE2}

Such mechanism would depend on the permissiveness of endothelial cells to allow SARSCoV2 to enter them via their basal membrane. Although, SARS-CoV2 has been shown to infect endothelial cells in-vitro and in-vivo (Monteil et al., 2020; Varga et al., 2020), the cellular surface through which viral entry occurs is uncertain. Monteil et al. (2020) has demonstrated that blood vessel organoids can be infected by SARS-CoV2 and that this infection depends on the ACE2 receptor. However, the path of endothelial entry was not determined. In fact, no experiments to date have studied whether the basal surface of polarised endothelial cells is susceptible to human coronavirus infection.

\section{Subcellular expression of ACE2 determines susceptibility to coronavirus infection}

Studies of polarised epithelial cell infection by SARS-CoV may shed light on endothelial susceptibility. In-vitro, polarised epithelial cells are readily infected by SARS-CoV at their apical surface, but are not susceptible to SARS-CoV infection through their base (Jia et al., 2005; Ren et al., 2006; Sims et al., 2008; Tseng et al., 2005). This has been explained by the fact that while ACE2, the receptor for SARS-CoV and SARS-CoV2 (Hoffmann et al., 2020; Li et al., 2003), is expressed in the apical surface of polarised epithelial cells, it is not expressed in the basal surface (Jia et al., 2005; Ren et al., 2006; Tseng et al., 2005). Thus, the 
susceptibility of a polarised cell to SARS-CoV2 infection may depend on the subcellular location of ACE2 receptor expression.

\section{Subcellular pattern of ACE2 expression in endothelial cells}

Endothelial cells are highly polarised (Worzfeld and Schwaninger, 2016) and are known to express ACE2 on their cell surface (Cao et al., 2012; Donoghue Mary et al., 2000). However, the subcellular localisation of ACE2 in endothelial cells has not been characterised. Nonetheless, it may be hypothesised that since ACE2 mediates the breakdown of the bloodborn angiotensin I and II (Donoghue Mary et al., 2000; Rice et al., 2004; Walker et al., 1976), ACE2 expression may be primarily located at the apical surface of endothelial cells, which faces the bloodstream.

\section{ACE2 independent infection of endothelial cells via their basal surface}

The presence of a coronavirus receptor at the basal cell surface appears to be necessary for viral entry at that site. As described above, SARS-CoV cannot infect the ACE2-deficient basal surface of epithelial cells. If ACE2 expression in polarised endothelial cells mirrors the pattern seen in epithelial cells, then SARS-CoV2 should not enter endothelial cells via their basal surface. Evidence for receptor mediated basal entry of Coronavirus is seen in MERS-CoV studies. MERS-CoV can infect the basal surface of polarised epithelial cells and this is associated with the presence of DPP4 in their basal surface (Tao et al., 2013) (Figure 1: B). Since there is evidence of endothelial infection in cases of Covid-19 (Chen et al., 2020; Varga et al., 2020), alternative receptors to ACE2 should be investigated as candidate mediators of SARS-CoV2 basal surface entry to endothelial cells.

\section{CD147 a novel mechanism for SARS-CoV2 entry}

CD147 has been proposed as an alternative receptor for SARS-CoV2 (Wang et al., 2020). CD147 a glycoprotein, previously identified as a putative receptor for SARS-CoV (Chen et al., 2005), has been shown to bind the SARS-CoV2 spike protein. In addition, antibodies against CD147 prevent SARS-CoV2 infection in vitro (Wang et al., 2020). Based on this evidence it has been proposed that CD147 may represent a novel invasive route for SARS-CoV2 (Wang et al., 2020). Interestingly, a randomised clinical trial using Meplazumab, a humanised antibody against CD147, for Covid-19 has been started and results from a preliminary trial appear promising (Bian et al., 2020; Tang-Du Hospital, 2020).

\section{Cellular pattern of CD147 expression}

CD147 is found throughout the body including the lungs (Jouneau et al., 2011; The Human Protein Atlas, 2020). It is expressed in the cell membrane of epithelial cells (Deora et al., 2005; Moheimani et al., 2018), T-cells (Hu et al., 2010; Koch et al., 1999) and endothelial cells (Maïssa et al., 2017; Patrizz et al., 2020). Physiologically, CD147 can preferentially localise to the basal domain of polarised cells, as it has a functional role in chaperoning carboxylate 
transporters to the basal surface of epithelial cells (Deora et al., 2005; Kirk et al., 2000). In addition, in pathological states it can activate matrix metalloproteinases (MMPs) at the basement membrane of epithelial and endothelial cells as a response to injury (El-Asrar et al., 2017; Gabison et al., 2005; Jouneau et al., 2011; Xie et al., 2019).

\section{CD147 mediates the entry of other viruses and microorganisms} Importantly, CD147, as a co-receptor, mediates target cell entry by other viruses and microorganisms including human immunodeficiency virus (HIV), cytomegalovirus (CMV), measles, chikungunya virus, Plasmodium falciparum and Neisseria meningitidis (Bernard et al., 2014; Caluwé et al., 2019; Crosnier et al., 2011; Pushkarsky et al., 2001; Vanarsdall et al., 2018; Watanabe et al., 2010). Specifically, CD147 allows for the endothelial colonisation by CMV (Vanarsdall et al., 2018) and Neisseria meningitidis (Bernard et al., 2014). This demonstrates that CD147 can mediate endothelial cell infection of pathogens that in the first instance infect epithelial cells.

\section{CD147 in endothelial stress and SARS-CoV2 infection}

It is important to note that CD147 expression and function are enhanced by proteins that have been implicated in the pathogenesis of human CoV disease (Sardu et al., 2020; Tanaka et al., 2013), namely cyclophilins and angiotensin II (Pons et al., 2011; Seizer et al., 2014). Interestingly, cyclophilins and angiotensin II also play roles in the endothelial dysfunction seen hypertension, diabetes and heart disease (Wang et al., 2010; Zhang et al., 2017). Given the apparent relationship between severe Covid-19 disease and the metabolic syndrome diseases (Dutta et al., 2020), as well as its relationship with SARS-CoV viraemia (Chen et al., 2020), CD147 represents a strong candidate as a mediator of SARS-CoV2 endothelial cell infection and viraemia in severe Covid-19 disease.

\section{Conclusion}

Thus, here we propose a mechanism of alveolar endothelial infection by SARS-CoV2 mediated by CD147 at the basal surface of endothelial cells. This may occur because alveolar epithelial cells release SARS-CoV2 particles from their basal surface to the shared basement membrane. In this mechanism, CD147 mediated SARS-CoV2 entry is promoted by the endothelial cellular stress associated with metabolic syndrome diseases (Figure 1: C).

Future work should help determine the validity of several assumptions on which this hypothetical mechanism is based. The following questions should be answered:

- Do infected alveolar epithelial cells release SARS-CoV2 at their basal surface in vivo?

- Can polarised endothelial cells be infected via the basal surface in vitro?

- What is the pattern of subcellular ACE2 expression in endothelial cells?

- Can CD147 mediate SARS-CoV2 entry into endothelial cells? 
- Does endothelial cellular stress change the pattern of SARS-CoV2 infectivity?

Tackling these questions may result in finding pharmacological and screening targets that could be used to alleviate the global burden of Covid-19.

\section{Contributors}

ADAS carried out the literature search and drafted the paper. ADAS and FCAS reviewed the evidence and formed the theoretical mechanism. FCAS revised the manuscript. ADAS and FCAS have reviewed the paper prior to submission. This manuscript has not been currently accepted or published elsewhere.

Declaration of interests

We declare no competing interests.

\section{Acknowledgments}

We are grateful to those publishers who provided unrestricted access to the literature reviewed in this paper. We dedicate this work to the front-line workers who put their life at risk to help others in such unprecedented times. 


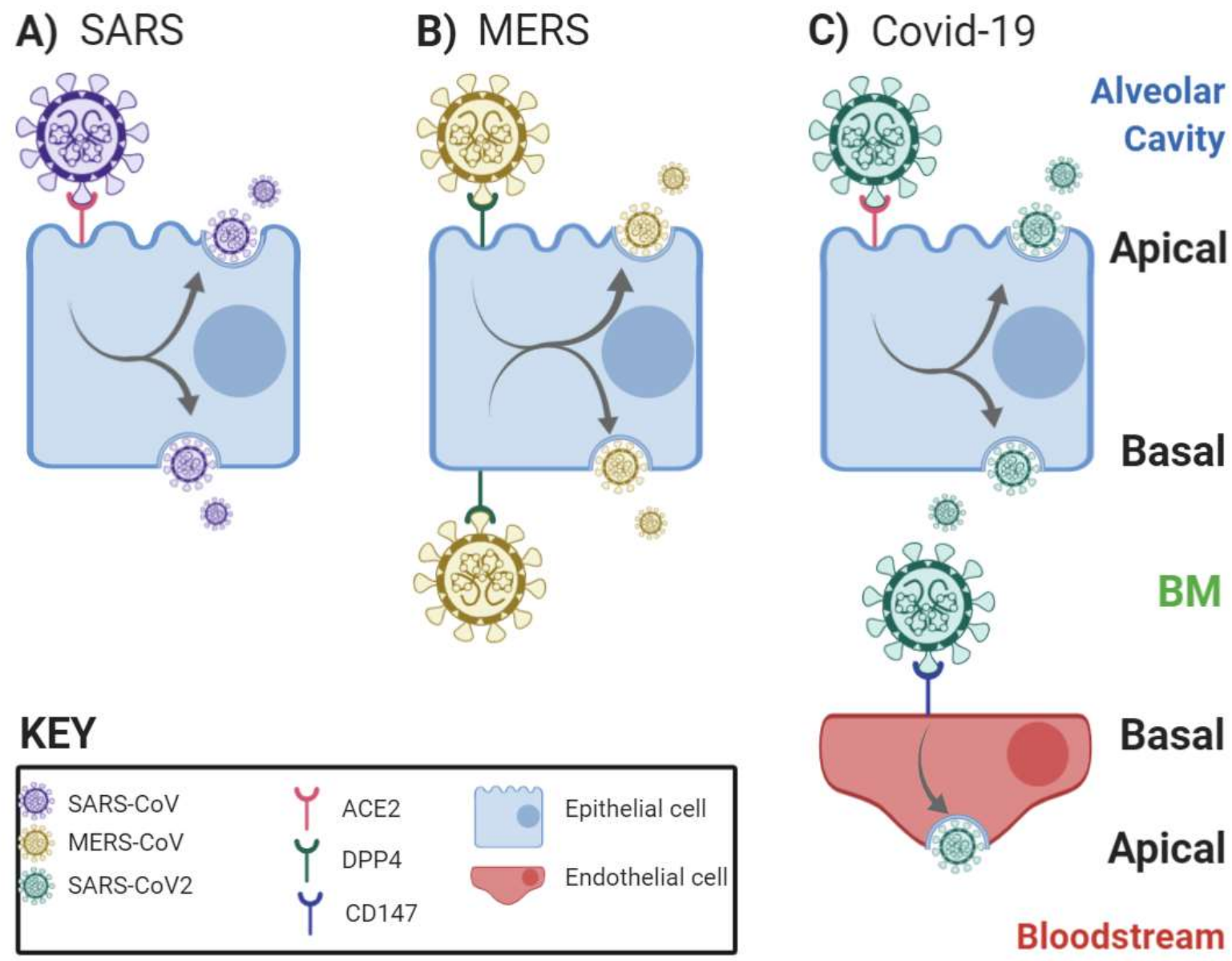

Figure 1. Polarised entry of human coronaviruses into epithelial and endothelial cells. A) SARS-CoV infects epithelial cells at their apical surface through the ACE2 receptor. B) MERS-CoV infects epithelial cells at their apical and basal surface through the DPP4 receptor. C) Proposed mechanism in Covid-19 SARS-CoV2 infection. SARS-CoV2 enters epithelial cells via ACE2. Progeny virus is released from the basal surface to the basement membrane (BM) shared with endothelial cells. There SARS-CoV2 enters endothelial cells via CD147 at their basal surface. Progeny virus is released via the apical domain of endothelial cells reaching the bloodstream. Note that progeny viral release occurs at both the apical and basal surface of infected epithelial cells with all viruses described above (A, B and C). Figure constructed using BioRender ${ }^{\circledR}$. 


\section{References}

Bernard, S.C., Simpson, N., Join-Lambert, O., Federici, C., Laran-Chich, M.-P., Maïssa, N., Bouzinba-Ségard, H., Morand, P.C., Chretien, F., Taouji, S., Chevet, E., Janel, S., Lafont, F., Coureuil, M., Segura, A., Niedergang, F., Marullo, S., Couraud, P.-O., Nassif, X., Bourdoulous, S., 2014. Pathogenic Neisseria meningitidis utilizes CD147 for vascular colonization. Nature Medicine 20, 725-731. https://doi.org/10.1038/nm.3563

Bian, H., Zheng, Z.-H., Wei, D., Zhang, Zheng, Kang, W.-Z., Hao, C.-Q., Dong, K., Kang, W., Xia, J.-L., Miao, J.-L., Xie, R.-H., Wang, B., Sun, X.-X., Yang, X.-M., Lin, P., Geng, J.J., Wang, K., Cui, H.-Y., Zhang, K., Chen, X.-C., Tang, H., Du, H., Yao, N., Liu, S.-S., Liu, L.-N., Zhang, Zhe, Gao, Z.-W., Nan, G., Wang, Q.-Y., Lian, J.-Q., Chen, Z.-N., Zhu, P., 2020. Meplazumab treats COVID-19 pneumonia: an open-labelled, concurrent controlled add-on clinical trial. medRxiv 2020.03.21.20040691. https://doi.org/10.1101/2020.03.21.20040691

Caluwé, L.D., Coppens, S., Daled, S., Dhaenens, M., Deforce, D., Ostade, X.V., Ariën, K., Bartholomeeusen, K., 2019. The Basigin (CD147)-CD98 protein complex is involved in Chikungunya virus attachment and entry in human cells. Access Microbiology, 1, 56. https://doi.org/10.1099/acmi.imav2019.po0032

Cao, L., Xu, L., Huang, B., Wu, L., 2012. Propofol increases angiotensin-converting enzyme 2 expression in human pulmonary artery endothelial cells. Pharmacology 90, 342347. https://doi.org/10.1159/000338754

Chen, X., Zhao, B., Qu, Y., Chen, Y., Xiong, J., Feng, Y., Men, D., Huang, Q., Liu, Y., Yang, B., Ding, J., Li, F., 2020. Detectable serum SARS-CoV-2 viral load (RNAaemia) is closely correlated with drastically elevated interleukin 6 (IL-6) level in critically ill COVID-19 patients. Clin Infect Dis. https://doi.org/10.1093/cid/ciaa449

Chen, Z., Mi, L., Xu, J., Yu, J., Wang, X., Jiang, J., Xing, J., Shang, P., Qian, A., Li, Y., Shaw, P.X., Wang, J., Duan, S., Ding, J., Fan, C., Zhang, Y., Yang, Y., Yu, X., Feng, Q., Li, B., Yao, X., Zhang, Z., Li, L., Xue, X., Zhu, P., 2005. Function of HAb18G/CD147 in Invasion of Host Cells by Severe Acute Respiratory Syndrome Coronavirus. J Infect Dis 191, 755-760. https://doi.org/10.1086/427811

Cong, Y., Ren, X., 2014. Coronavirus entry and release in polarized epithelial cells: a review. Reviews in Medical Virology 24, 308-315. https://doi.org/10.1002/rmv.1792

Crosnier, C., Bustamante, L.Y., Bartholdson, S.J., Bei, A.K., Theron, M., Uchikawa, M., Mboup, S., Ndir, O., Kwiatkowski, D.P., Duraisingh, M.T., Rayner, J.C., Wright, G.J., 2011. Basigin is a receptor essential for erythrocyte invasion by Plasmodium falciparum. Nature 480, 534-537. https://doi.org/10.1038/nature10606

Deora, A.A., Philp, N., Hu, J., Bok, D., Rodriguez-Boulan, E., 2005. Mechanisms regulating tissue-specific polarity of monocarboxylate transporters and their chaperone CD147 in kidney and retinal epithelia. PNAS 102, 16245-16250. https://doi.org/10.1073/pnas.0504419102

Donoghue Mary, Hsieh Frank, Baronas Elizabeth, Godbout Kevin, Gosselin Michael, Stagliano Nancy, Donovan Michael, Woolf Betty, Robison Keith, Jeyaseelan Raju, Breitbart Roger E., Acton Susan, 2000. A Novel Angiotensin-Converting EnzymeRelated Carboxypeptidase (ACE2) Converts Angiotensin I to Angiotensin 1-9. Circulation Research 87, e1-e9. https://doi.org/10.1161/01.RES.87.5.e1

Dutta, D., Priya, G., Joshi, A., 2020. COVID-19 and Metabolic Syndrome - An Association too Difficult to Ignore. touchENDOCRINOLOGY.

El-Asrar, A.M.A., Ahmad, A., Alam, K., Siddiquei, M.M., Mohammad, G., Hertogh, G.D., Mousa, A., Opdenakker, G., 2017. Extracellular matrix metalloproteinase inducer (EMMPRIN) is a potential biomarker of angiogenesis in proliferative diabetic retinopathy. Acta Ophthalmologica 95, 697-704. https://doi.org/10.1111/aos.13284

Gabison, E.E., Mourah, S., Steinfels, E., Yan, L., Hoang-Xuan, T., Watsky, M.A., Wever, B.D., Calvo, F., Mauviel, A., Menashi, S., 2005. Differential Expression of Extracellular Matrix Metalloproteinase Inducer (CD147) in Normal and Ulcerated 
Corneas: Role in Epithelio-Stromal Interactions and Matrix Metalloproteinase Induction. The American Journal of Pathology 166, 209-219.

https://doi.org/10.1016/S0002-9440(10)62245-6

He, X.W., Lai, J.S., Cheng, J., Wang, M.W., Liu, Y.J., Xiao, Z.C., Xu, C., Li, S.S., Zeng, H.S., 2020. [Impact of complicated myocardial injury on the clinical outcome of severe or critically ill COVID-19 patients]. Zhonghua Xin Xue Guan Bing Za Zhi 48, E011. https://doi.org/10.3760/cma.j.cn112148-20200228-00137

Hoffmann, M., Kleine-Weber, H., Schroeder, S., Krüger, N., Herrler, T., Erichsen, S., Schiergens, T.S., Herrler, G., Wu, N.-H., Nitsche, A., Müller, M.A., Drosten, C., Pöhlmann, S., 2020. SARS-CoV-2 Cell Entry Depends on ACE2 and TMPRSS2 and Is Blocked by a Clinically Proven Protease Inhibitor. Cell 181, 271-280.e8. https://doi.org/10.1016/j.cell.2020.02.052

Hu, J., Dang, N., Yao, H., Li, Y., Zhang, H., Yang, X., Xu, J., Bian, H., Xing, J., Zhu, P., Chen, Z., 2010. Involvement of HAb18G/CD147 in T cell activation and immunological synapse formation. J Cell Mol Med 14, 2132-2143. https://doi.org/10.1111/j.1582-4934.2010.01012.x

Huang, C., Wang, Y., Li, X., Ren, L., Zhao, J., Hu, Y., Zhang, L., Fan, G., Xu, J., Gu, X., Cheng, Z., Yu, T., Xia, J., Wei, Y., Wu, W., Xie, X., Yin, W., Li, H., Liu, M., Xiao, Y., Gao, H., Guo, L., Xie, J., Wang, G., Jiang, R., Gao, Z., Jin, Q., Wang, J., Cao, B., 2020. Clinical features of patients infected with 2019 novel coronavirus in Wuhan, China. The Lancet 395, 497-506. https://doi.org/10.1016/S0140-6736(20)30183-5

Jia, H.P., Look, D.C., Shi, L., Hickey, M., Pewe, L., Netland, J., Farzan, M., WohlfordLenane, C., Perlman, S., McCray, P.B., 2005. ACE2 Receptor Expression and Severe Acute Respiratory Syndrome Coronavirus Infection Depend on Differentiation of Human Airway Epithelia. Journal of Virology 79, 14614-14621. https://doi.org/10.1128/JVI.79.23.14614-14621.2005

Jouneau, S., Khorasani, N., Souza, P.D., Macedo, P., Zhu, J., Bhavsar, P.K., Chung, K.F., 2011. EMMPRIN (CD147) regulation of MMP-9 in bronchial epithelial cells in COPD. Respirology 16, 705-712. https://doi.org/10.1111/j.1440-1843.2011.01960.x

Kirk, P., Wilson, M.C., Heddle, C., Brown, M.H., Barclay, A.N., Halestrap, A.P., 2000. CD147 is tightly associated with lactate transporters MCT1 and MCT4 and facilitates their cell surface expression. EMBO J 19, 3896-3904. https://doi.org/10.1093/emboj/19.15.3896

Koch, C., Staffler, G., Hüttinger, R., Hilgert, I., Prager, E., Černý, J., Steinlein, P., Majdic, O., Hořejší, V., Stockinger, H., 1999. T cell activation-associated epitopes of CD147 in regulation of the $\mathrm{T}$ cell response, and their definition by antibody affinity and antigen density. Int Immunol 11, 777-786. https://doi.org/10.1093/intimm/11.5.777

Li, W., Moore, M.J., Vasilieva, N., Sui, J., Wong, S.K., Berne, M.A., Somasundaran, M., Sullivan, J.L., Luzuriaga, K., Greenough, T.C., Choe, H., Farzan, M., 2003. Angiotensin-converting enzyme 2 is a functional receptor for the SARS coronavirus. Nature 426, 450-454. https://doi.org/10.1038/nature02145

Maïssa, N., Covarelli, V., Janel, S., Durel, B., Simpson, N., Bernard, S.C., Pardo-Lopez, L., Bouzinba-Ségard, H., Faure, C., Scott, M.G.H., Coureuil, M., Morand, P.C., Lafont, F., Nassif, X., Marullo, S., Bourdoulous, S., 2017. Strength of Neisseria meningitidis binding to endothelial cells requires highly-ordered CD147/ 32 -adrenoceptor clusters assembled by alpha-actinin-4. Nature Communications 8, 15764. https://doi.org/10.1038/ncomms15764

Moheimani, F., Koops, J., Williams, T., Reid, A.T., Hansbro, P.M., Wark, P.A., Knight, D.A., 2018. Influenza A virus infection dysregulates the expression of microRNA-22 and its targets; CD147 and HDAC4, in epithelium of asthmatics. Respiratory Research 19, 145. https://doi.org/10.1186/s12931-018-0851-7

Monteil, V., Kwon, H., Prado, P., Hagelkrüys, A., Wimmer, R.A., Stahl, M., Leopoldi, A., Garreta, E., Hurtado Del Pozo, C., Prosper, F., Romero, J.P., Wirnsberger, G., Zhang, H., Slutsky, A.S., Conder, R., Montserrat, N., Mirazimi, A., Penninger, J.M., 2020. Inhibition of SARS-CoV-2 Infections in Engineered Human Tissues Using 
Clinical-Grade Soluble Human ACE2. Cell 181, 905-913.e7.

https://doi.org/10.1016/j.cell.2020.04.004

Morgenroth, K., Ebsen, M., 2008. CHAPTER 8 - Anatomy, in: Papadakos, P.J., Lachmann, B., Visser-Isles, L. (Eds.), Mechanical Ventilation. W.B. Saunders, Philadelphia, pp. 69-85. https://doi.org/10.1016/B978-0-7216-0186-1.50012-0

OECD, 2020. Coronavirus (COVID-19): Joint actions to win the war [WWW Document]. URL https://www.oecd.org/about/secretary-general/ (accessed 5.20.20).

Patrizz, A., Doran, S.J., Chauhan, A., Ahnstedt, H., Roy-O'Reilly, M., Lai, Y.-J., Weston, G., Tarabishy, S., Patel, A.R., Verma, R., Staff, I., Kofler, J.K., Li, J., Liu, F., Ritzel, R.M., McCullough, L.D., 2020. EMMPRIN/CD147 plays a detrimental role in clinical and experimental ischemic stroke. Aging 12, 5121-5139.

https://doi.org/10.18632/aging.102935

Pons, M., Cousins, S.W., Alcazar, O., Striker, G.E., Marin-Castaño, M.E., 2011. Angiotensin II-Induced MMP-2 Activity and MMP-14 and Basigin Protein Expression Are Mediated via the Angiotensin II Receptor Type 1-Mitogen-Activated Protein Kinase 1 Pathway in Retinal Pigment Epithelium. Am J Pathol 178, 2665-2681. https://doi.org/10.1016/j.ajpath.2011.02.006

Pushkarsky, T., Zybarth, G., Dubrovsky, L., Yurchenko, V., Tang, H., Guo, H., Toole, B., Sherry, B., Bukrinsky, M., 2001. CD147 facilitates HIV-1 infection by interacting with virus-associated cyclophilin A. PNAS 98, 6360-6365. https://doi.org/10.1073/pnas.111583198

Pyrc, K., Sims, A.C., Dijkman, R., Jebbink, M., Long, C., Deming, D., Donaldson, E., Vabret, A., Baric, R., Hoek, L. van der, Pickles, R., 2010. Culturing the Unculturable: Human Coronavirus HKU1 Infects, Replicates, and Produces Progeny Virions in Human Ciliated Airway Epithelial Cell Cultures. Journal of Virology 84, 11255-11263. https://doi.org/10.1128/JVI.00947-10

Ren, X., Glende, J., Al-Falah, M., de Vries, V., Schwegmann-Wessels, C., Qu, X., Tan, L., Tschernig, T., Deng, H., Naim, H.Y., Herrler, G., 2006. Analysis of ACE2 in polarized epithelial cells: surface expression and function as receptor for severe acute respiratory syndrome-associated coronavirus. Journal of General Virology, 87, 16911695. https://doi.org/10.1099/vir.0.81749-0

Rice, G.I., Thomas, D.A., Grant, P.J., Turner, A.J., Hooper, N.M., 2004. Evaluation of angiotensin-converting enzyme (ACE), its homologue ACE2 and neprilysin in angiotensin peptide metabolism. Biochem J 383, 45-51. https://doi.org/10.1042/BJ20040634

Sardu, C., Gambardella, J., Morelli, M.B., Wang, X., Marfella, R., Santulli, G., 2020. Is COVID-19 an Endothelial Disease? Clinical and Basic Evidence. https://doi.org/10.20944/preprints202004.0204.v1

Seizer, P., Gawaz, M., May, A.E., 2014. Cyclophilin A and EMMPRIN (CD147) in cardiovascular diseases. Cardiovasc Res 102, 17-23. https://doi.org/10.1093/cvr/cvu035

Sims, A.C., Burkett, S.E., Yount, B., Pickles, R.J., 2008. SARS-CoV replication and pathogenesis in an in vitro model of the human conducting airway epithelium. Virus Res 133, 33-44. https://doi.org/10.1016/j.virusres.2007.03.013

Tanaka, Y., Sato, Y., Sasaki, T., 2013. Suppression of Coronavirus Replication by Cyclophilin Inhibitors. Viruses 5, 1250-1260. https://doi.org/10.3390/v5051250

Tang-Du Hospital, 2020. Single Center, Single Arm, Open Clinical Study to Access Safety and Initial Efficacy of Anti-CD147 Humanized Meplazumab for Injection to Treat With 2019-nCoV Pneumonia (Clinical trial registration No. NCT04275245). clinicaltrials.gov.

Tao, X., Hill, T.E., Morimoto, C., Peters, C.J., Ksiazek, T.G., Tseng, C.-T.K., 2013. Bilateral Entry and Release of Middle East Respiratory Syndrome Coronavirus Induces Profound Apoptosis of Human Bronchial Epithelial Cells. Journal of Virology 87, 9953-9958. https://doi.org/10.1128/JVI.01562-13 
The Human Protein Atlas, 2020. BSG protein expression- Summary [WWW Document]. URL https://www.proteinatlas.org/ENSG00000172270-BSG (accessed 5.19.20).

Tseng, C.-T.K., Tseng, J., Perrone, L., Worthy, M., Popov, V., Peters, C.J., 2005. Apical Entry and Release of Severe Acute Respiratory Syndrome-Associated Coronavirus in Polarized Calu-3 Lung Epithelial Cells. J Virol 79, 9470-9479. https://doi.org/10.1128/JVI.79.15.9470-9479.2005

Vanarsdall, A.L., Pritchard, S.R., Wisner, T.W., Liu, J., Jardetzky, T.S., Johnson, D.C., 2018. CD147 Promotes Entry of Pentamer-Expressing Human Cytomegalovirus into Epithelial and Endothelial Cells. mBio 9. https://doi.org/10.1128/mBio.00781-18

Varga, Z., Flammer, A.J., Steiger, P., Haberecker, M., Andermatt, R., Zinkernagel, A.S., Mehra, M.R., Schuepbach, R.A., Ruschitzka, F., Moch, H., 2020. Endothelial cell infection and endotheliitis in COVID-19. The Lancet 395, 1417-1418. https://doi.org/10.1016/S0140-6736(20)30937-5

Walker, W.G., Moore, M.A., Horvath, J.S., Whelton, P.K., 1976. Arterial and venous angiotensin II in normal subjects. Relation to plasma renin activity and plasma aldosterone concentration, and response to posture and volume changes. Circ. Res. 38, 477-483. https://doi.org/10.1161/01.res.38.6.477

Wang, C.-H., Li, F., Takahashi, N., 2010. The renin angiotensin system and the metabolic syndrome. Open Hypertens J 3, 1-13. https://doi.org/10.2174/1876526203010001

Wang, G., Deering, C., Macke, M., Shao, J., Burns, R., Blau, D.M., Holmes, K.V., Davidson, B.L., Perlman, S., McCray, P.B., 2000. Human Coronavirus 229E Infects Polarized Airway Epithelia from the Apical Surface. Journal of Virology 74, 9234-9239. https://doi.org/10.1128/JVI.74.19.9234-9239.2000

Wang, K., Chen, W., Zhou, Y.-S., Lian, J.-Q., Zhang, Z., Du, P., Zhang, G.Y., Cui, H.-Y., Geng, J.-J., Wang, B., Sun, X.-X., Wang, C.-F., Yang, X., Lin, P., Deng, Y.-Q., Wei, D., Yang, X.-M., Zhu, Y.-M., Zhang, K., Zheng, Z.-H., Miao, J.-L., Guo, T., Shi, Y., Zhang, J., Fu, L., Wang, Q.-Y., Bian, H., Zhu, P., Chen, Z.-N., 2020. SARS-CoV-2 invades host cells via a novel route: CD147-spike protein. bioRxiv.

Watanabe, A., Yoneda, M., Ikeda, F., Terao-Muto, Y., Sato, H., Kai, C., 2010. CD147/EMMPRIN Acts as a Functional Entry Receptor for Measles Virus on Epithelial Cells. Journal of Virology 84, 4183-4193. https://doi.org/10.1128/JVI.02168-09

Worzfeld, T., Schwaninger, M., 2016. Apicobasal polarity of brain endothelial cells. J Cereb Blood Flow Metab 36, 340-362. https://doi.org/10.1177/0271678X15608644

Xie, Y., Wang, Y., Ding, H., Guo, M., Wang, X., Dong, Q., Cui, M., 2019. Highly glycosylated CD147 promotes hemorrhagic transformation after rt-PA treatment in diabetes: a novel therapeutic target? Journal of Neuroinflammation 16, 72. https://doi.org/10.1186/s12974-019-1460-1

Yang, J., Zheng, Y., Gou, X., Pu, K., Chen, Z., Guo, Q., Ji, R., Wang, H., Wang, Y., Zhou, $Y$., 2020. Prevalence of comorbidities and its effects in patients infected with SARSCoV-2: a systematic review and meta-analysis. Int. J. Infect. Dis. 94, 91-95. https://doi.org/10.1016/j.ijid.2020.03.017

Zhang, H., Fan, Q., Xie, H., Lu, L., Tao, R., Wang, F., Xi, R., Hu, J., Chen, Q., Shen, W., Zhang, R., Yan, X., 2017. Elevated Serum Cyclophilin B Levels Are Associated with the Prevalence and Severity of Metabolic Syndrome. Front. Endocrinol. 8. https://doi.org/10.3389/fendo.2017.00360

Zhou, F., Yu, T., Du, R., Fan, G., Liu, Y., Liu, Z., Xiang, J., Wang, Y., Song, B., Gu, X., Guan, L., Wei, Y., Li, H., Wu, X., Xu, J., Tu, S., Zhang, Y., Chen, H., Cao, B., 2020. Clinical course and risk factors for mortality of adult inpatients with COVID-19 in Wuhan, China: a retrospective cohort study. The Lancet 395, 1054-1062. https://doi.org/10.1016/S0140-6736(20)30566-3 